\title{
Zapnik, Jörg, Pest und Krieg im Ostseeraum, Der « Schwarze Tod » in Stralsund während des Großen Nordischen Krieges (1700-1721)
}

Jean-Luc Le Cam

\section{OpenEdition}

Édition électronique

URL : http://journals.openedition.org/ifha/1711

DOI : 10.4000/ifha.1711

ISSN : 2198-8943

\section{Éditeur}

IFRA - Institut franco-allemand (sciences historiques et sociales)

\section{Référence électronique}

Jean-Luc Le Cam, «Zapnik, Jörg, Pest und Krieg im Ostseeraum, Der « Schwarze Tod » in Stralsund während des Großen Nordischen Krieges (1700-1721) », Revue de I'IFHA [En ligne], Date de recension, mis en ligne le 01 janvier 2008, consulté le 22 septembre 2020. URL : http://journals.openedition.org/ifha/ 1711 ; DOI : https://doi.org/10.4000/ifha.1711

Ce document a été généré automatiquement le 22 septembre 2020.

(C)IFHA 


\title{
Zapnik, Jörg, Pest und Krieg im Ostseeraum, Der «Schwarze Tod" in Stralsund während des Großen Nordischen Krieges (1700-1721)
}

\author{
Jean-Luc Le Cam
}

La dernière grande peste en Allemagne fut celle qui toucha le Nord(-Est) du pays et particulièrement les ports de la Baltique de 1708 à 1712 avec une acmé en 1710. La région cumulait plusieurs facteurs favorables à l'épidémie : cette méditerranée du Nord d'abord, sur laquelle croisaient en tous sens navires marchands et passagers, ces ports où les voyageurs se mêlaient aux populations de la ville et de l'hinterland, et enfin, à cette époque, la Grande Guerre du Nord qui selon l'opinion générale, servit de catalyseur au désastre à cause des déplacements massifs de troupes et de fuyards qu'elle impliquait. Cette catastrophe relativement bien documentée par rapport aux épidémies antérieures a certes focalisé l'attention des historiens depuis longtemps mais fait encore l'objet de travaux récents dans une perspective historiographique renouvelée (voir les actes du récent colloque édité par Stefan Kroll et Kersten Krüger : Städtesystem und Urbanisierung im Ostseeraum in der Frühen Neuzeit. Urbane Lebensräume und Historische Informationssysteme. Beiträge des wissenschaftlichen Kolloquiums in Rostock vom 15. und 16. November 2004, Münster/ Hamburg/ London : LIT, 2006, il comprend cinq contributions sur le sujet, dont celle de J. Zapnik). Ainsi cette thèse soutenue à l'Université de Greifswald, qui se propose à partir de l'exemple de la ville de Stralsund d'étudier le rapport entre maladie et société, notamment en retraçant par quels moyens la société urbaine de l'époque moderne faisait face à la menace exceptionnelle que constituait la peste. Stralsund, port important inséré dans les réseaux commerciaux mais aussi forteresse et garnison essentielle à la position suédoise en Allemagne du Nord, fut par ces deux aspects rapidement impliquée dans l'épidémie. Après une présentation rapide de la Poméranie suédoise de 1648 jusqu'en 1720-21, fin de la guerre du Nord, puis de l'histoire de Stralsund, l'ouvrage étudie les caractéristiques de l'épidémie dans le sud et l'est de l'espace baltique, en fait dans les 
villes allemandes des pays baltes et de Prusse orientale. À partir de la p. 59 commence l'étude monographique de la peste à Stralsund de 1710 à 1711. D'abord les mécanismes de l'irruption du phénomène et les réactions des diverses autorités provinciales et urbaines : la retraite du corps d'armée de Krassow de Grande-Pologne jusqu'à la Poméranie suédoise eut pour conséquence la progression de l'épidémie d'est en ouest, de Pologne jusqu'en Suède et au Danemark, et en Allemagne du Nord. L'auteur montre comment et par quel biais les autorités obtiennent les informations sur la progression de l'épidémie, de la rumeur plus ou moins imaginaire au diagnostic précis en passant par les correspondances. Puis comment se met en place la lutte contre l'épidémie à travers une ordonnance (Pestordnung : Stettin 1709, Stralsund 1710) qui prévoit notamment la constitution d'une autorité municipale spécialisée (le Collegium sanitatis) qui est avant tout politique car formée de quelques conseillers municipaux et représentants des quartiers. On suit comment ce Collegium sanitatis s'efforce avec difficulté de recruter et de diriger les personnels spécialement chargés de s'occuper des malades et des morts (les Pestbediente, qui vont du Pestchirurg au Pestprediger), de prendre les mesures de quarantaine et de salubrité publique, les rapports, parfois conflictuels, entre les différentes autorités, Collegium sanitatis, conseil municipal, garnison, gouvernement de Stettin. L'étude envisage ensuite les conséquences économiques de l'épidémie du fait de la fermeture de marchés et des frontières, de la chute des recettes fiscales et du coût des mesures sanitaires. La partie démographique se fonde sur les estimations, corrigées, de l'époque (3609 morts soit $29,5 \%$ de la population), sur les registres paroissiaux et les actes de tutelle et de l'orphelinat. Elle établit une certaine surmortalité des professions en contact avec la mer ou l'eau. Elle s'efforce aussi de reconstituer une "topographie de la mort " en cartographiant les décès dus à la maladie semaine après semaine de juin à décembre 1710. L'ouvrage se termine par la description du retour à la normale. L'auteur reconnaît ne pas avoir pu explorer une partie de sa problématique faute de sources suffisantes, par exemple le rapport entre médecins et malades ou l'expérience individuelle de la maladie et regrette l'absence de véritables statistiques de l'épidémie.

2 Il nous semble cependant que le principal problème n'est pas là mais dans la mauvaise exploitation des sources existantes du fait de l'absence de maîtrise des outils et des méthodes de l'histoire sérielle et de la démographie historique. On ne saurait ici faire le relevé des erreurs que comporte cette étude dans les choix d'exploitations graphiques et statistiques des registres paroissiaux, qui seraient reprochées à un débutant en maitrise. On peut les résumer comme une succession de résultats tronçonnés desquels ne peut émerger une interprétation correcte des phénomènes. Le texte se contente de paraphraser les données collectées ou de faire des suppositions sans se donner les moyens de les étayer. Cela sans doute parce que l'auteur ne s'appuie en rien sur les acquis de plusieurs décennies de démographie historique européenne dont on cherche en vain les références en bas de page du chapitre (les quelques rappels obligés en introduction sur l'état de la recherche ne sont là visiblement que pour la forme). L'hypothèse intéressante d'une surexposition des métiers du port aurait dû être étayée par un calcul d'écart à l'indépendance ou un test de CHI2 et surtout confrontée à une estimation des effectifs et la localisation des populations de référence. Au lieu de cela, l'auteur se contente d'une exploitation impressionniste et fort peu convaincante des cartes hebdomadaires, elles mêmes faussées par une symbologie non proportionnelle en surface, sans jamais faire de synthèse sur les six mois observés. Bref, on comprendra que l'ouvrage vaut plus par son étude de l'organisation du système de lutte contre la 
peste que par celle des effets véritables de l'épidémie sur la société urbaine, qui reste à reprendre.

3 Jean-Luc Le Cam (Université de Brest) 